\title{
THE USE OF CARROT SEED OIL (DAUCUS CAROTA L.) TO FORMULATE NANOEMULGELS AS AN EFFECTIVE NATURAL SUNSCREEN AND SKIN ANTI-AGING
}

\section{ANAYANTI ARIANTO*, HAKIM BANGUN, SUMAIYAH, CHRISTY NATASYA DWI YANTI PUTRI SIREGAR}

Faculty of Pharmacy, Center of Excellence Nanomedicine Innovation, Universitas Sumatera Utara, Medan 20155, Indonesia

*Email: anayanti@usu.ac.id

Received: 29 Oct 2021, Revised and Accepted: 06 Dec 2021

\begin{abstract}
Objective: The purpose of this study was to develop a nanoemulgel containing vegetable oil of carrot seed oil as an effective natural sunscreen and skin anti-aging.

Methods: Nanoemulgels containing 4\% carrot seed oil were formulated in three formulas with different ratios of Tween 80 and Sorbitol and prepared by using the high-energy emulsification method. The nanoemulgels were determined for the organoleptic characteristic, globule size, $\mathrm{pH}$ physical stability during storage for $12 \mathrm{w}$ at three different temperatures (room, high and low temperature), centrifugation, and cycling test. The Sun Protection Factor (SPF) value was determined by UV spectrophotometric method and the effectiveness of anti-aging was evaluated by using a skin analyzer and the results were compared with sunscreen emulgel.

Results: Nanoemulgel containing $4 \%$ carrot seed oil with a ratio of Tween 80 as surfactant and Sorbitol as co-surfactant 40 and 20 resulted in the smallest mean droplet size of $338.34 \mathrm{~nm}$ and the sizes were increased during $12 \mathrm{w}$ of storage at room temperature but still in the nano size and this nanoemulgel did not show phase separation or still stable. These nanoemulgels were also stable after the centrifugation and cycling test. The emulgel preparation was not stable or showed phase separation after the centrifugation test. The SPF value obtained from the nanoemulgel was $20.28 \pm 0.22$ and these values were higher than the sunscreen emulgel $(13.94 \pm 0.27)$. The pore size, spot, and wrinkles of the volunteer skin were reduced after using the nanoemulgel containing $4 \%$ carrot seed.
\end{abstract}

Conclusion: The sunscreen and skin anti-aging activity of nanoemulgel preparation containing $4 \%$ carrot seed oil with a ratio of surfactant Tween 80 and co-surfactant Sorbitol 40 and 20 were more effective compare with emulgel preparation.

Keywords: Carrot seed oil, Nanoemulgel, Sunscreen, Skin anti-aging

(C) 2022 The Authors. Published by Innovare Academic Sciences Pvt Ltd. This is an open access article under the CC BY license (https://creativecommons.org/licenses/by/4.0/) DOI: https://dx.doi.org/10.22159/ijap.2022v14i1.43481. Journal homepage: https://innovareacademics.in/journals/index.php/ijap

\section{INTRODUCTION}

UV radiation in the skin induces oxidative free radicals, such as superoxide, hydrogen peroxide, and highly reactive hydroxyl radicals that strongly attack macromolecules such as proteins, lipids, RNA, and DNA, changing their structure and interfering with their function, which can cause oxidative stress [1]. Oxidative stress can cause cell damage and death in the skin and cause skin aging. The visible signs of aging on the skin, including dry skin appearance, scalping, wrinkling, pigmentation, and photoaging correlate with cancer risk $[2,3]$. The use of sunscreen is necessary for the precautions recommended by dermatologists and public health campaigns aimed at reducing sunburn, premature skin aging, and skin cancer [4].

Some chemical sunscreen ingredients show undesirable effects from sunscreen products such as irritation, allergy, phototoxicity, and photoallergy [4]. Therefore, the use of natural sunscreen ingredients such as carrot seed oil can reduce this effect. Carrot seed oil is an essential oil obtained by extraction from carrot seeds (Daucus carota L.). The most essential oil content is carotol, fatty acids, $\beta$-carotene in large amounts and $\alpha$ and $\gamma$ carotene in small amounts, $\alpha$-carotene, and $\beta$-carotene are partially metabolized to vitamin A $[5,6]$. Carrot seed oil is an antioxidant, antiseptic, antifungal, and fragrant with a high vitamin A content and can be used as a sunscreen, anti-aging, skin revitalizing, and rejuvenating ingredient $[7,8]$. Topical administration of preparation containing active ingredients from natural ingredients provides sunscreen and skin anti-aging effects with a broad spectrum, namely the effect of sunscreen on UV radiation and as antioxidant might help to reduce the reactive oxygen species causes of aging [9]. Nowadays, the use of cosmetics with active ingredients that have dual anti-aging and sun activity protection (sunscreen) is very useful and practical. Nanotechnology has become a technology that can improve the stability and efficiency of cosmetic preparation [10].

The purpose of this study was to investigate sunscreen effectiveness on SPF value of nanoemulgel containing carrot seed oil by in vitro spectrophotometry method and anti-aging effectiveness by using skin analyzer. Nanoemulgels were made by incorporating nanoemulsions into a gel matrix. The nanoemulgel has the advantage that it can increase the stability of the nanoemulsion by reducing surface tension, improve the patient's acceptability because it had good dispersibility, was not greasy, easy to apply, and increase the penetration of lipophilic active ingredients like vegetable oil (carrot seed oil) into the skin thereby increasing the effectiveness of the active ingredients $[11,12]$.

\section{MATERIALS AND METHODS}

The active ingredient used in this study was Carrot Seed Oil (Happy green store, Jakarta Indonesia), Carbopol 940, sodium carboxymethyl cellulose, glycerol, propylene glycol, sorbitol, methylparaben, propylparaben, Tween 80, Triethanolamine, Span 80, buffer solution pH 7.01, buffer solution pH 4.01 were purchased from CV Rudang Jaya, Medan, Indonesia. All ingredients were analytical grade.

Nanoemulsions containing carrot seed oil were prepared through a high-energy emulsification method $[13,14]$ by using a magnetic stirrer and ultrasonicator. Tween 80 and sorbitol are used as surfactants and co-surfactans. The nanoemulsion system consists of the oil and the water phase. The oil phase consists of carrot seed oil and sorbitol. In the water phase, methylparaben and propylparaben as preservatives were dissolved in distilled water, then heated by using the hot plate (Fisons); this solution was added Tween 80 and stirred at $3000 \mathrm{rpm}$ by magnetic stirrer (Boeco, Germany) for $8 \mathrm{~h}$. The oil phase was mixed into the water phase and stirred at 3000 $\mathrm{rpm}$ with a magnetic stirrer (Boeco, Germany) for $8 \mathrm{~h}$, then sonicated for $30 \mathrm{~s}$ by ultrasonicator (Ultrasonic Cleaner Branson 1510 E-MT, USA) until a transparent nanoemulsion was formed. Carbopol 940 was dispersed in pure water and added with TEA to pH-6.5 to obtain a gel base of $1 \%$ Carbopol 940 solution [15]. Nanoemulgels were prepared by mixing the obtained nanoemulsion containing carrot seed oil with a gel base of 1\% Carbopol 940 (ratio 
of nanoemulsion and gel base 4:1), then stirred using a magnetic stirrer at $3000 \mathrm{rpm}$ for $10 \mathrm{~h}$ and ultrasonicated for $2 \mathrm{~h}$ until a transparent nanoemulgels were produced [16].

The preparation of emulgel containing $4 \%$ carrot seed oil was prepared by mixing carrot seed oi and Span 80 , then this oil phase was heated to $70^{\circ} \mathrm{C}$. The preservatives (methyl and propyl parabens) were dissolved in propylene glycol and glycerol and added CMC Na solution and this water phase was heated to $70{ }^{\circ} \mathrm{C}$. After that, the oil phase was added to the water phase and stir with a magnetic stirrer for $45 \mathrm{~min}$ to produce a homogenous emulsion [17]. Emulgel was obtained by mixing the obtained emulsion with a gel base of $2 \%$ of Carbopol 940 (ratio of emulsion and gel 4:1) with gentle stirring for $10 \mathrm{~min}$.

The mean droplet size for nanoemulgel and emulgel formulations was measured by Particle Size Analyzer Fritsch Analysette 22 NanoTec. The $\mathrm{pH}$ measurement is done using $1 \%$ nanoemulgel solution in pure water with a digital $\mathrm{pH}$ meter (Hanna instrument). Viscosity measurement was carried out using the NDJ-8S Viscometer and viscosity value was measured every $2 \mathrm{w}$ for $12 \mathrm{w}$ of storage at room temperature physical stability evaluation was done by storing it is at $25 \pm 2{ }^{\circ} \mathrm{C}$ (room temperature), $40 \pm 2{ }^{\circ} \mathrm{C}$ (high temperature), $75 \pm 5 \% \mathrm{RH}$ and $4 \pm 2{ }^{\circ} \mathrm{C}$ (low temperature) for $12 \mathrm{w}$, then observed the nanoemulgels and gel preparation through visual inspection for their color, odor, and phase separation with observation every w [18].

Cycling test of the nanoemulgels and emulgel containing $4 \%$ carrot seed oil was done by putting it is in the freezer at $4 \pm 2{ }^{\circ} \mathrm{C}$ for $24 \mathrm{~h}$ and then put in Climatic Chamber (Memmert, Germany) at $40 \pm 2{ }^{\circ} \mathrm{C}$ for $24 \mathrm{~h}$ and repeated in 6 cycles. Centrifugation test was done using centrifuges (Hitachi CF 16 R X II, Japan) with a rotation of $3750 \mathrm{rpm}$ for $5 \mathrm{~h}$ at $25 \pm 2{ }^{\circ} \mathrm{C}$. The physical stability of the nanoemulgels and emulgel was observed [19].

The morphology and droplet size of nanoemulgel and emulgel containing $4 \%$ carrot seed oil was analyzed using a transmission electron microscope (JEOL JEM 1400, Japan). Sunscreen activity was evaluated by diluting the preparation using $96 \%$ ethanol to a concentration of $200 \mu \mathrm{g}$ per ml. Absorption spectra of nanoemulgels and emulgel were measured by using UV-visible (Shimadzu UV 1800, Japan). After that, the sunscreen activity (SPF) was calculated by the Mansur equation. Six determinations were made for each sample [20].

Anti-aging efficacy measurement was performed on 6 volunteers by using a skin analyzer (Aram, Huvis, Co., Ltd, Korea). The volunteers were accommodated in an air-conditioned room at $25 \pm 1{ }^{\circ} \mathrm{C}$ and $45 \pm 5 \%$ relative humidity for $15 \mathrm{~min}$ before the measurements. The selected nanoemulgel preparation containing $4 \%$ carrot seed oil was applied 2 times every day for $28 \mathrm{~d}$. The moisture content, pore, evenness, spot, and wrinkles of skin were measured before the application of nanoemulgel on day 0 and after application at days 7 , 14,21 , and 28. Approval to conduct the in vivo studies was obtained from the Research Ethics Committee of Universitas Sumatera Utara (No. 166/KEP/USU/2020).

\section{RESULTS}

Carrot seed oil nanoemulsion was prepared by using a variation of the ratio between Tween 80 as surfactant and sorbitol as cosurfactant. The resulting nanoemulsion was added with a gel solution of carbopol 940 to produce nanoemulgel. The composition of nanoemulgel and emulgel can be seen in tables 1 and 2 .

Table 1: Composition of carrot seed oil nanoemulgels

\begin{tabular}{|c|c|c|c|c|}
\hline & \multicolumn{3}{|c|}{ Qantity of $100 \mathrm{ml}(\% \mathrm{w} / \mathrm{v})$} & \multirow{2}{*}{$\begin{array}{l}\text { Ratio of nanoemulsion with } \\
\text { gel base }\end{array}$} \\
\hline & F1 & F2 & F3 & \\
\hline \multicolumn{5}{|c|}{ Ingredients of nanoemulsion } \\
\hline carrot seed oil & 5 & 5 & 5 & \multirow{6}{*}{$80 \mathrm{ml}$} \\
\hline Tween 80 & 40 & 38 & 36 & \\
\hline Sorbitol & 20 & 22 & 24 & \\
\hline Methylparaben & 0.10 & 0.10 & 0.10 & \\
\hline Propylparaben & 0.02 & 0.02 & 0.02 & \\
\hline Distilled water to & 100 & 100 & 100 & \\
\hline \multicolumn{5}{|c|}{ Ingredients of gel base } \\
\hline Carbopol 940 & 1.0 & 1.0 & 1.0 & \multirow[t]{3}{*}{$20 \mathrm{ml}$} \\
\hline TEA & 1.0 & 1.0 & 1.0 & \\
\hline Distilled water to & 100 & 100 & 100 & \\
\hline
\end{tabular}

Table 2: Composition of carrot seed oil emulgel

\begin{tabular}{|c|c|c|}
\hline & Quantity of $100 \mathrm{ml}(\% \mathrm{w} / \mathrm{v})$ & Ratio of nanoemulsion with gel base \\
\hline Ingredients of emulsion carrot seed oil & 5.00 & \\
\hline Tween 80 & 1.26 & \\
\hline Span 80 & 3.73 & \\
\hline $\mathrm{CMC} \mathrm{Na}$ & 1.00 & $80 \mathrm{ml}$ \\
\hline Propylen glycol & 10.00 & \\
\hline Methylparaben & 0.10 & \\
\hline Propylparaben & 0.02 & \\
\hline Distilled water to & 100 & \\
\hline \multicolumn{3}{|l|}{ Ingredients of gel base } \\
\hline Carbopol 940 & 1.00 & \\
\hline TEA & 1.00 & $20 \mathrm{ml}$ \\
\hline Distilled water to & 100 & \\
\hline
\end{tabular}

All preparations of carrot seed oil nanoemulgel were yellow and translucent and this appearance did not change during $12 \mathrm{w}$ of storage at room temperature but the consistency of carrot seed oil emulgel becomes liquid as shown in fig. 1.

The nanoemulgel containing carrot seed oil obtained in this study had a smaller droplet size than the emulgel formulation. The emulgel preparation has a droplet size of $5028.37 \mathrm{~nm}$. The droplet size of the nanoemulgel containing carrot seed oil increased during $12 \mathrm{w}$ of storage at room temperature, but the droplet was still in the nanosize as presented in table 3 .

Table 4 shows that the decrease in $\mathrm{pH}$ and viscosity value of the emulgel containing carrot seed oil was greater than that of the nanoemulgel preparations during $12 \mathrm{w}$ of storage at room temperature. 

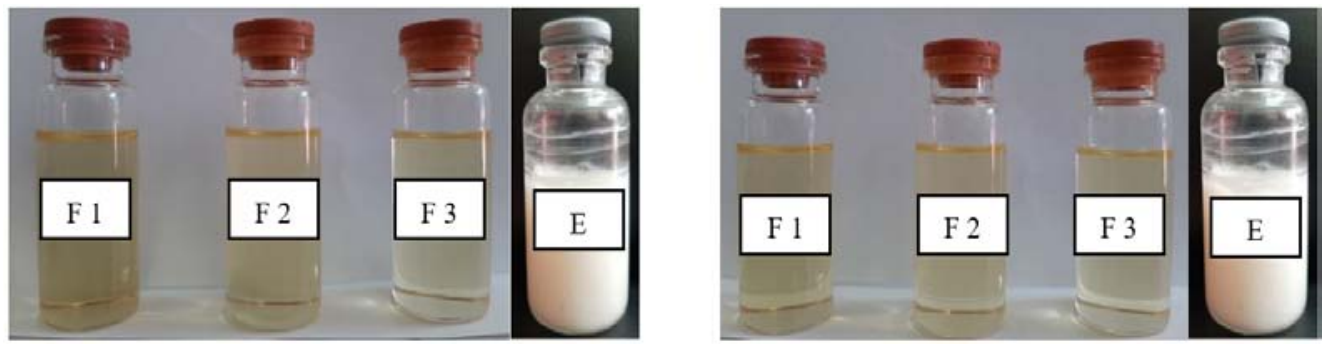

Fig. 1: Appearance of carrot seed oil nanoemulgels (F1, F2, and F3) and emulgel (E)

Table 3: The mean droplet size for nanoemulgel preparations

\begin{tabular}{lll}
\hline Formula code & Time $(\mathbf{w})$ & Mean droplet size (nm) \\
\hline & 0 & 338.34 \\
F1 & 4 & 411.86 \\
& 8 & 512.27 \\
& 12 & 607.23 \\
F2 & 0 & 401.29 \\
& 4 & 416.27 \\
& 8 & 532.15 \\
F3 & 12 & 645.20 \\
& 0 & 401.29 \\
& 4 & 470.31 \\
& 8 & 583.63 \\
\hline
\end{tabular}

Table 4: Viscosity and pH value of nanoemulgel and emulgel containing carrot seed oil

\begin{tabular}{llll}
\hline Formula code & Time $(\mathbf{w})$ & $\mathbf{p H ~ ( n = 3 )}$ & Viscosity (mPas) (n=3) \\
\hline F1 & 0 & $6.90 \pm 0.00$ & $499,00 \pm 0.00$ \\
& 4 & $6.80 \pm 0.00$ & $454.33 \pm 1.15$ \\
& 8 & $6.53 \pm 0.06$ & $439.00 \pm 1.73$ \\
F2 & 12 & $6.13 \pm 0.06$ & $422.33 \pm 2.52$ \\
& 0 & $6.87 \pm 0.06$ & $486.33 \pm 1.15$ \\
& 4 & $6.70 \pm 0.00$ & $455.00 \pm 0.00$ \\
F3 & 8 & $6,47 \pm 0,06$ & $441.33 \pm 1.15$ \\
& 12 & $6.13 \pm 0.06$ & $417.33 \pm 2.31$ \\
& 0 & $6.87 \pm 0.06$ & $475.33 \pm 3.51$ \\
Emulgel & 4 & $6.77 \pm 0.06$ & $454.00 \pm 1.73$ \\
& 8 & $6.43 \pm 0.06$ & $437.67 \pm 1.15$ \\
& 12 & $6.07 \pm 0.06$ & $411.67 \pm 2.89$ \\
& 0 & $6.97 \pm 0.06$ & $1998.00 \pm 0,00$ \\
& 4 & $6.67 \pm 0.06$ & $1530.00 \pm 4.62$ \\
\end{tabular}

The color and odor of nanoemulgel remain unchanged; there is no phase separation after storage for $12 \mathrm{w}$ at low and high temperatures as can be seen in fig. 2.

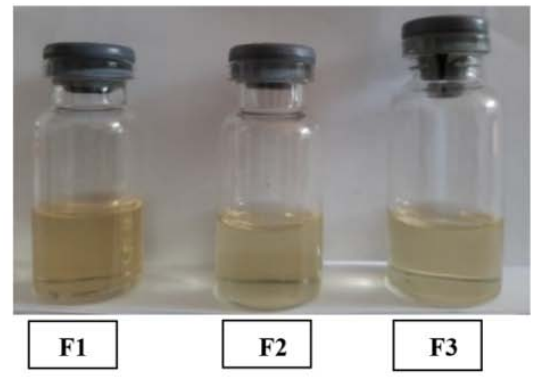

A

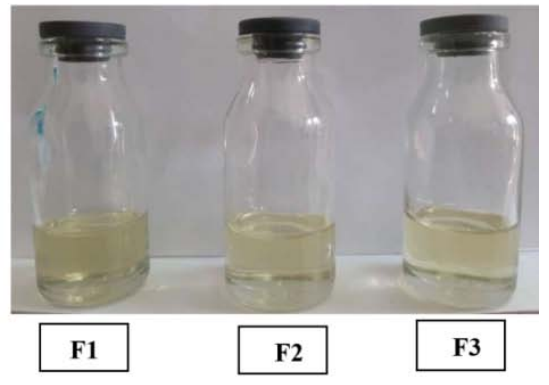

B

Fig. 2: Appearance of carrot seed oil nanoemulgels after storage for $12 \mathrm{w}$ at low temperature (A) and high temperature (B)

The result of the cycling test of nanoemulgel preparation did not find any phase separation (fig 3). There was phase separation in the emulgel preparation after the centrifugation test, but the physical form of nanoemulgel preparations did not change as shown in fig. 4. 


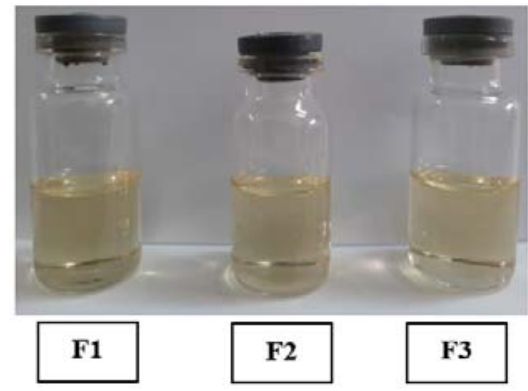

$\mathbf{A}$

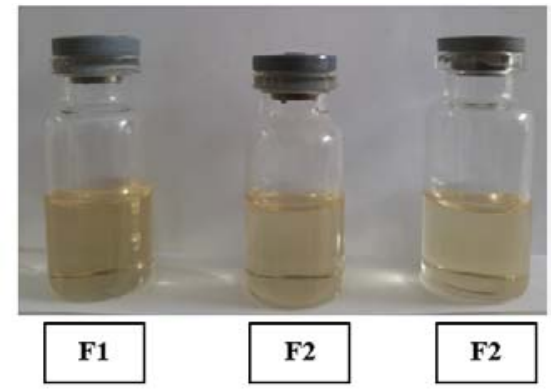

B

Fig. 3: Cycling test result of carrot seed oil nanoemulgel preparations (A: Before Test, B: After Test)

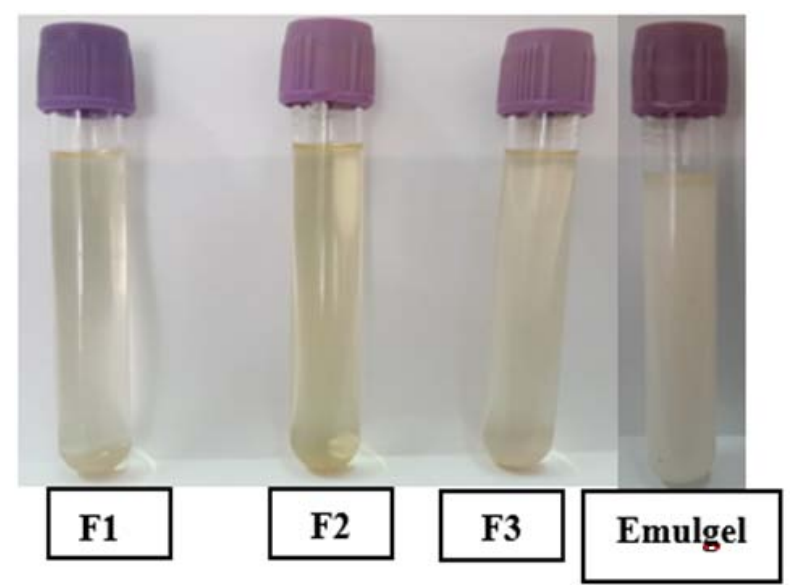

Fig. 4: Centrifugation test result of carrot seed oil nanoemulgels and emulgel

To study the morphology and distribution of nanoemulgel and emulgel, transmission electron microscopy photomicrographs were taken, as shown in fig. 5. It was observed that nanoemulgel has a uniform dispersion, spherical without any aggregation and the droplet size was smaller than emulgel preparation.

The nanoemulgel containing carrot seed oil showed a higher SPF value than emulgel preparation (table 5). The results of SPF determination revealed that carrot seed oil in the form nanoemulgel exhibits greater UVR protection.
Table 5: SPF value of nanoemulgel and emulgel containing carrot seed oil

\begin{tabular}{ll}
\hline Formulation code & Sun protection factor (SPF) value \\
\hline F1 & $20.28 \pm 0.218$ \\
F2 & $19.33 \pm 0.280$ \\
F3 & $16.59 \pm 0.190$ \\
Emulgel & $13.94 \pm 0.266$ \\
\hline
\end{tabular}

Notes: Data is presented as mean \pm SD, $n=6$

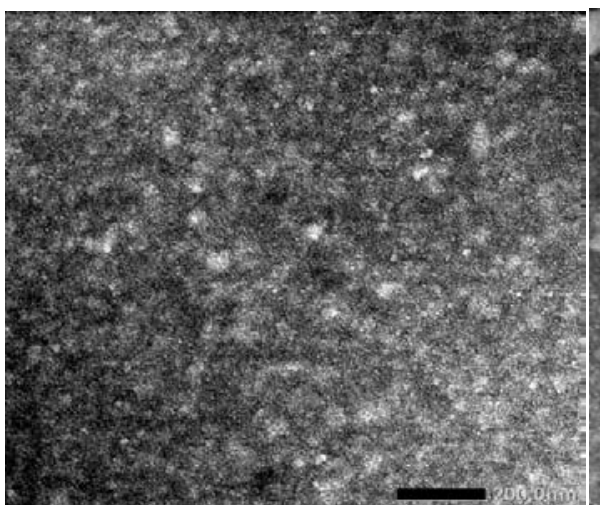

A

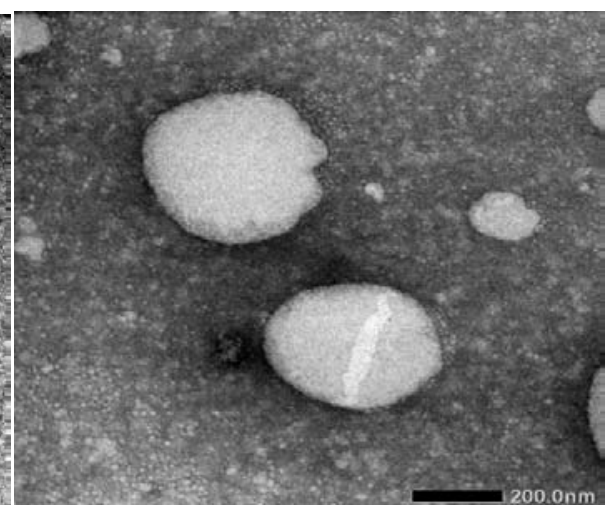

B

Fig. 5: TEM images of nanoemulgel (A) and emulgel (B) containing carrot seed oil $4 \%$

Nanoemulgel F1 which has the highest SPF values were chosen to evaluate the effectiveness of anti-aging on skin volunteers. The parameters of anti-aging activity evaluation include measurement of moisture content, pore size, evenness, spot, and wrinkles. The skin anti-aging measurement results can be seen in table 6 and table 7 . The moisture content of volunteers increases after the application of nanoemulgel and emulgel from dehydrated skin to normal skin. The pore size of the volunteer skin was reduced from 
some large $(41.33 \pm 2.8)$ to excellence $(18.00 \pm 1.4)$, the spot from many spots $(40.50 \pm 2.7)$ to little spot $(18.66 \pm 3.0)$, and wrinkles from wrinkles $(43.33 \pm 3.5)$ to approach fine line $(20.50 \pm 2.1)$ after using the nanoemulgel containing $4 \%$ carrot seed (F1) for $4 \mathrm{w}$. The volunteer's skin becomes smooth $(27.16 \pm 1.4)$ after using nanoemulgel for $2 \mathrm{w}$. The condition of pore size, spot, evenness, and wrinkles of volunteer skin did not change after using emulgel for $4 \mathrm{w}$.

Table 6: Moisture content (\%) results of nanoemulgel (F1) and emulgel containing carrot seed oil 4\% on skin volunteers

\begin{tabular}{|c|c|c|c|c|c|}
\hline \multirow[t]{2}{*}{ Formulation code } & \multicolumn{5}{|c|}{ Time (Week) } \\
\hline & $\mathbf{0}$ & 1 & 2 & 3 & 4 \\
\hline F1 & $27.83 \pm 1.4$ & $31.5 \pm 1.3$ & $35.33 \pm 1.2$ & $38.66 \pm 1.2$ & $42.16 \pm 0.7$ \\
\hline Emulgel & $28.10 \pm 1.4$ & $29,83 \pm 1.4$ & $32.16 \pm 1.1$ & $34.00 \pm 1.2$ & $35.83 \pm 1.1$ \\
\hline
\end{tabular}

Notes: Data is presented as mean $\pm S D, n=6$, Dehidrated 0-29\%, Normal 30-50, Hidrated 51-100

Table 7: Pore, evenness, spot, wrinkles measurement results on skin volunteers

\begin{tabular}{|c|c|c|c|c|c|}
\hline \multirow{2}{*}{ Formulation code } & \multirow{2}{*}{ Time (week) } & \multicolumn{4}{|c|}{ Average of score } \\
\hline & & Pore & Evenness & Spot & Wrinkles \\
\hline \multirow[t]{5}{*}{ Nanoemulgel (F1) } & 0 & $41.33 \pm 2.8$ & $36.33 \pm 1.6$ & $40.50 \pm 2.7$ & $43.33 \pm 3.5$ \\
\hline & 1 & $35.50 \pm 2.1$ & $33.50 \pm 3.3$ & $34.83 \pm 2.8$ & $37.83 \pm 3.0$ \\
\hline & 2 & $28.83 \pm 1.4$ & $31.10 \pm 2.2$ & $29.00 \pm 3.0$ & $30.66 \pm 3.0$ \\
\hline & 3 & $24.00 \pm 1.4$ & $29.33 \pm 1.6$ & $23.83 \pm 3.3$ & $23.83 \pm 2.5$ \\
\hline & 4 & $18.00 \pm 1.4$ & $27.16 \pm 1.4$ & $18.66 \pm 3.0$ & $20.50 \pm 2.1$ \\
\hline \multirow[t]{5}{*}{ Emulgel } & 0 & $40.00 \pm 2.0$ & $38.00 \pm 1.5$ & $41.00 \pm 2,3$ & $41.66 \pm 2.1$ \\
\hline & 1 & $37.66 \pm 2.0$ & $36.30 \pm 1.7$ & $36.33 \pm 2.3$ & $38.50 \pm 1.8$ \\
\hline & 2 & $35.66 \pm 1.9$ & $34.30 \pm 0.8$ & $34.16 \pm 1.7$ & $33.66 \pm 3.3$ \\
\hline & 3 & $33.83 \pm 1.7$ & $32.80 \pm 0.7$ & $32.16 \pm 1.7$ & $30.66 \pm 3.3$ \\
\hline & 4 & $31.66 \pm 1.8$ & $31.10 \pm 0.7$ & $29.83 \pm 1.7$ & $27.16 \pm 2.2$ \\
\hline
\end{tabular}

Notes: Data is presented as mean $\pm \mathrm{SD}, \mathrm{n}=6$

\section{DISCUSSION}

There are two methods for nanoemulsion preparation: the highenergy method in which a mechanical device is used and the lowenergy method in which the chemical potential of the component is used [21]. In this study nanoemulgel containing carrot seed oil preparations have been successfully formulated using Tween 80 as a surfactant, Sorbitol as a co-surfactant, and Carbopol 940 as a gelling agent used in addition to the formulation to facilitate the stabilization process. Carbopol 940 has advantages such as being non-toxic, biocompatible, bioadhesive (long residence time on the skin) [22]. The amount of Carbopol 940 used is $0.5 \%$, which was sufficient to produce nanoemulgels translucent, non-greasy, and easy to spread. The addition of Trietanolamin in the formulation can form a good and stable gel matrix at a $\mathrm{pH}$ around 6-7. The $\mathrm{pH}$ value of nanoemulgels obtained still meets the $\mathrm{pH}$ standard for topical preparations suitable with skin pH balance (4.5-6.5) [23] and the viscosity only slightly decreases after storage for $12 \mathrm{w}$ at room temperature. The nanoemulgels with small droplets around 200-300 $\mathrm{nm}$ were achieved by using the high-energy method (combining high shear stirring and ultrasonic emulsification) and the nanoemulgels have remained stable, no phase separation, creaming, sedimentation, or color change occurred after storage for $12 \mathrm{w}$ under three different temperature $\left(25 \pm 2{ }^{\circ} \mathrm{C}, 40 \pm 2{ }^{\circ} \mathrm{C}\right.$, and $\left.4 \pm 2{ }^{\circ} \mathrm{C}\right)$. The nanoemulgel formulation $\mathrm{F} 1$ with the optimum amount of surfactant and co-surfactant shows the smallest droplet size.

The nanoemulgels were stable after the centrifugation test. The small droplet size of the nanoemulgels can resist the physical destabilization caused by gravitational separation, flocculation, and/or coalescence. It also avoids the creaming process because the droplet's Brownian motion is enough to overcome the gravitational separation force. Due to very small globule size and less surface tension between the oil and water molecules in nanoemulgel, it almost has not the tendency to agglomerate or precipitate, which reduces the possibility of creaming or sedimentation. As a result, nanoemulgel is much more stable than emulgel system, and the nanoemulgels would be stable for at least one y [24].

The SPF value of nanemulgel preparations is higher than that of emulgel, this is due to the small size of the globules, which will increase the solubility of carrot seed oil, so it will absorb more ultraviolet light, which results in higher SPF values.
Oxidative stress is considered to be one of the main mechanisms involved in skin aging [25] Carrot seed oil contains beta carotene that has antioxidant activity can be useful for preventing and treating skin aging. However, beta carotene is very lipophilic, so that penetration into deep layers of the skin is only slightly; therefore in this study, the carrot seed oil was formulated in nanoemulgel to increase the penetration of antioxidants for increasing anti-aging activity.

The anti-aging activity of nanoemulgel containing 4\% carrot seed oil (F1) was higher than that of emulgel preparation with the same concentration of carrot seed oil. This is because the smaller globule size of nanoemulgel can pass through the pores on the skin easily, thereby increasing the penetration of the active ingredients into the skin $[26,27]$.

\section{CONCLUSION}

Carrot seed oil can be formulated into nanoemulgels using Tween 80 as surfactant and Sorbitol. as co-surfactant and physically stable on stability test. Nanoemulgel containing $4 \%$ carrot seed oil with a ratio of Tween 80 and Sorbitol 40 and 20 (formulation code F1) has the smallest droplet size of $338.34 \mathrm{~nm}$ and showed the highest SPF value of $20.28 \pm 0.22$ and most effective of activity skin anti-aging. The SPF value and activity skin anti-aging of nanoemulgels are more effective compare with emulgel preparation. The emulgel preparation showed phase separation after the centrifugation test.

\section{ACKNOWLEDGMENT}

The Authors are extremely grateful to the Head of the research institute, Universitas Sumatera Utara, Prof. Dr. Erman Munir, M. Sc. who has facilitated this research.

\section{FUNDING}

This work was financially supported by Universitas Sumatera Utara, Medan, Indonesia, through the TALENTA Research, scheme of Penelitian Dasar 2020 (research contract number: 44/UN5.2.3.1/PPM/SPP-TALENTA USU/2020).

\section{AUTHORS CONTRIBUTIONS}

All the authors have contributed equally.

\section{CONFLICT OF INTERESTS}

The authors report no conflicts of interest in this work. 


\section{REFERENCES}

1. D'Orazio J, Jarrett $S$, Amaro Ortiz A, Scott T. UV radiation and the skin. Int J Mol Sci. 2013;14(6):12222-48. doi: 10.3390/ijms140612222, PMID 23749111.

2. Amaro Ortiz A, Yan B, D'Orazio JA. Ultraviolet radiation, aging and the skin: prevention of damage by topical cAMP manipulation. Molecules. 2014;19(5):6202-19. doi: $10.3390 /$ molecules19056202. PMID 24838074.

3. Shanbhag S, Nayak A, Narayan R, Nayak UY. Anti-aging and sunscreens: paradigm shift in cosmetics. Adv Pharm Bull. 2019;9(3):348-59. doi: 10.15171/apb.2019.042, PMID 31592127.

4. Heurung AR, Raju SI, Warshaw EM. Adverse reactions to sunscreen agents: epidemiology, responsible irritants and allergens, clinical characteristics, and management. Dermatitis. 2014;25(6):289-326. doi: 10.1097/DER.0000000000000079, PMID 25384223.

5. Ozcan MM, Chalchat CJ. Chemical composition of carrot seed oil (Daucus carota L.) cultivated in Turkey: characterization of the seed oil and essential oil. Grasas Aceites 2007;58(4):359-62. doi: 58.i4.447:org10.3989/gya.2007.

6. Pal RS, Pal Y, Saraswat N, Wal P, Wal A. Current review on herbs for derma care. Open Dermatol J. 2019;13(1):41-6. doi: $10.2174 / 1874372201913010041$

7. Goswami PK, Samant M, Srivastava R. Natural sunscreen agents. Sch Acad J Pharmacol. 2013;2(6):458-63.

8. Kothapalli L, Kamble P. Formulation and evaluation of seed oils for their antioxidant activity and sunscreening effect. Int Res J Pharm. 2018;9(7):159-67. doi: 10.7897/2230-8407.097142.

9. Nash JF, Tanner PR. Relevance of UV filter/sunscreen product photostability to human safety. Photodermatol Photoimmunol Photomed. 2014;30(2-3):88-95. doi: 10.1111/phpp.12113, PMID 24433498.

10. Leelapornpisid $\mathrm{P}$, Kiattisin $\mathrm{K}$, Jantrawut $\mathrm{P}$, Phrutivorapongkul A. Nanoemulsion loaded with marigol flower extract (Tagetes erecta linn) in gel preparation as an anti-wrinkles cosmeceutical. IJPPS 2014;6(2):231-6. Doi: http://cmuir.cmu.acther/jspui/handle/6653943832/53890.

11. Eid AM. Preparation, characterization and anti-inflammatory activity of swietenia macrophylla nanoemulgel. J Nanomed Nanotechnol. 2014;5(2). doi: 10.4172/2157-7439.1000190.

12. Jivani NM, Patel CP, Prajapati BG. Nanoemulgel innovative approach for topical gel-based formulations. Res Rev Health Care Open ACC J 2018:18-23. doi: 10.32474/RRHOAJ.2018.01.000107.

13. Delmas T, Piraux H, Couffin AC, Texier I, Vinet F, Poulin P, Cates $\mathrm{ME}$, Bibette J. How to prepare and stabilize very small nanoemulsions. Langmuir. 2011;27(5):1683-92. doi: 10.1021/la104221q, PMID 21226496.

14. Koroleva MY, Yurtov EV. Nanoemulsions: the properties, methods of preparation and promising applications. Russ Chem
Rev.

2012;81(1):21-43.

doi:

10.1070/RC2012v081n01ABEH004219.

15. Chodankar DS, Kudchadkar SS, Gude RS, Navti PD, Sawant SM. Formulation optimization and evaluation of flurbiprofen emulgel. Int J Pharm Pharm Sci 2020;12(8):49-54. doi: 10.22159/ijpps.2020v12i8.37330.

16. Arianto A, Lie DYL, S Bangun HB. Preparation and evaluation of nanoemulgels containing a combination of grape seed oil and anisotriazine as sunscreen. Open Access Maced J Med Sci 2020;8(B):994-9. doi: 10.3889/oamjms.2020.5293.

17. Estanqueiro M, Conceição J, Amaral MH, Santos D, Silva JB, Lobo JMS. Characterization and stability studies of emulsion systems containing pumice. Braz J Pharm Sci. 2014;50(2):361-9. doi: 10.1590/S1984-82502014000200016.

18. Ali MS, Alam MS, Alam N, Anwer T, Safhi MM. Accelerated stability testing of a clobetasol propionate-loaded nanoemulsion as per ICH guidelines. Sci Pharm. 2013;81(4):1089-100. doi: 10.3797/scipharm.1210-02, PMID 24482775 .

19. Iradhati $\mathrm{AH}$, Jufri $\mathrm{M}$. Formulation and physical stability test of griseofulvin microemulsion gel. Int J Appl Pharm 2017;9(1):227. doi: 10.22159/ijap.2017.v9s1.22_27.

20. Dutra EA, Oliveira DAGdC, Kedor-Hackmann ERM, Santoro MIRM. Determination of sun protection factor (SPF) of sunscreens by ultraviolet spectrophotometry. Rev Bras Cienc Farm. 2004;40(3):381-5. doi: 10.1590/S151693322004000300014

21. Yukuyama MN, Ghisleni DDM, Pinto TJA, Bou-Chacra NA. Nanoemulsion: process selection and application in cosmetics-a review. Int J Cosmet Sci. 2016;38(1):13-24. doi: 10.1111/ics.12260, PMID 26171789.

22. Parente ME, Ochoa Andrade A, Ares G, Russo F, Jimenez Kairuz A. Bioadhesive hydrogels for cosmetic applications. Int J Cosmet Sci. 2015;37(5):511-8. doi: 10.1111/ics.12227, PMID 25854849.

23. Chikakane $\mathrm{K}$, Takahashi $\mathrm{H}$. Measurement of skin $\mathrm{pH}$ and its significance in cutaneous diseases. Clin Dermatol. 1995;13(4):299-306. doi: 10.1016/0738-081x(95)00076-r, PMID 8665438.

24. Lachman L, Lieberman HA, Kanig JL. Theory and practice of Industrial pharmacy. Jakarta: Universitas Indonesia Press; 1994.

25. Montenegro L. Nanocarriers for skin delivery of cosmetic antioxidants. J Pharm Pharmacogn Res. 2014;2(4):73-92.

26. Sutradhar BK, Amin Lutfur MD. Nanoemulsions: increasing possibilities in drug delivery. Eur J Nanomed. 2013;5(2):97110. doi: 10.1515/ejnm-2013-0001.

27. Fadhila M, Munim A, Jufri M. Preparation, characterization, and in vitro skin penetration of morus alba root extract nanoemulsion. AJPCR. 2019;12(8):292-6. doi: 10.22159/ ajpcr.2019. v12i18.34313. 